\title{
LEARNING PHACOEMULSIFICATION: THE SURGEON-IN-TRAINING
}

\author{
H. TABANDEH ${ }^{1}$, B. SMEETS ${ }^{2}$, M. TEIMORY ${ }^{2}$ and H. SEWARD ${ }^{2}$ \\ Croydon and London
}

\begin{abstract}
SUMMARY
With the increasing trend towards phacoemulsification a perceived increased complication rate during the learning curve gives rise to a dilemma as to the best stage at which a surgeon-in-training can safely learn the technique. We prospectively analysed the complications and visual outcome of the first 160 phacoemulsification procedures performed by three surgeons-in-training. The main outcome measures included posterior capsule tear, vitreous and nuclear loss, surgical re-intervention rate and visual outcome. Posterior capsule tear occurred in 7 eyes $(4.4 \%)$ and vitreous loss in $6(3.8 \%)$. No nucleus was lost in the vitreous. Surgical re-intervention was required in 1 eye. Best corrected visual acuity was $6 / 12$ or better in 88\% of eyes. These results compare favourably with reports of surgeons-in-training learning extracapsular surgery and also with recently reported phacoemulsification series. This study indicates that with careful case selection and supervision phacoemulsification can be a safe procedure.
\end{abstract}

With the advent of small-incision cataract surgery phacoemulsification is enjoying a second wave of popularity. A survey of the American Cataract and Refractive Surgery Society showed phacoemulsification to be preferred to extracapsular cataract surgery by $52 \%$ of the members.' The United Kingdom practice is also rapidly changing towards phacoemulsification.

Phacoemulsification is based upon a different principle and involves different techniques from that of extracapsular cataract surgery. In order to perform phacoemulsification the surgeon needs to acquire new surgical skills. During the period of gaining experience in these new techniques there may be a higher incidence of complications. $\mathrm{Kelman}^{2}$ reported a $16 \%$ incidence of vitreous loss in the early days of phacoemulsification. Since its introduction by Kelman in the 1960s the technique has undergone pro-

From: 'St George's Hospital, London; ${ }^{2}$ Croydon Eye Unit, Croydon, UK.

Correspondence to: H. Tabandeh, MRCP, FRCOphth, Professorial Unit, Institute of Ophthalmology, Moorfields Eye Hospital, London EC IV 2PD, UK. gressive evolution. Advances in the design of lens implants and instrumentation, introduction of viscoelastics and modification of the surgical techniques on the basis of further experience have refined the procedure. However, despite its refinement and improved safety, there is still an increased complication rate during the learning period. ${ }^{3-6}$ Allinson et al. ${ }^{4}$ and Cruz et al. ${ }^{5}$ have documented complications that occurred whilst surgeonsin-training were learning phacoemulsification. The incidence of complications, together with the potential to inflict greater damage, give rise to a dilemma as to the best stage at which a surgeon-in-training can start learning phacoemulsification.

In United Kingdom the registrar grade contributes significantly to the total number of cataract operations that are performed annually. The complication rate and visual outcome achieved by the junior surgeon has implications for the overall morbidity associated with cataract surgery as well as for surgical training in this country. However, there are no reports on the surgical complications when phacoemulsification is performed by the registrar.

This report documents the operative and immediate post-operative complications as well as the visual outcome of all phacoemulsification procedures that were performed during the learning period of three surgeonsin-training.

\section{PATIENTS AND METHODS}

Data were collected prospectively on the first 160 phacoemulsification procedures performed by three ophthalmology registrars over a period of 1 year. The main outcome measures included posterior capsular tear, zonular dehiscence, vitreous loss, surgical re-intervention and the final corrected visual acuity.

\section{Patients}

Patients who were admitted for cataract surgery were assessed pre-operatively with regard to their suitability for phacoemulsification. Patients with only eye, advanced nuclear sclerosis, poorly dilating pupils and significant 
corneal opacities were considered unsuitable for phacoemulsification during the learning period of the registrars and were either operated on by a senior surgeon or underwent planned extracapsular cataract surgery.

\section{Surgeons}

Three surgeons-in-training were involved in the study. Each was in the fourth year of ophthalmology training and had performed over 150 cases of extracapsular surgery before undertaking phacoemulsification. Prior phacoemulsification teaching included attending lectures and wet laboratories and assisting in phacoemulsification procedures. Various stages of the procedure such as capsulorhexis, hydrodissection and automated irrigation and aspiration were practised during extracapsular cataract surgery. The procedure was supervised by two advanced phaco surgeons and feedback given during and following the procedures.

\section{Surgical Technique}

One hundred and fifty-four cases (96\%) were performed with the patient under local anaesthesia and 6 patients had a planned general anaesthetic. A superior rectus bridle suture was used to fix the globe in all cases. An inferior suture was employed when considered necessary. A 3 $\mathrm{mm}$ phacoemulsification incision was made superiorly, initially within the anterior sclera, moving posteriorly as more experience was gained. The incision was later extended to 5.5 or $6 \mathrm{~mm}$ for the insertion of lens implants. A second stab incision was made at 2 o'clock. Continuous curvilinear capsulorhexis, hydrodissection and in-the-bag phacoemulsification with nuclear fracture was performed in all cases. Wound closure was performed with a 10/0 nylon suture in a bootlace or interrupted configuration. A viscoelastic material was used in every procedure. A phacoemulsification machine incorporating a Venturi pump system was employed throughout the study.

\section{RESULTS}

One hundred and sixty patients with a mean age of 74.9 years (range 56-93 years) were included in the series. Two surgeons performed 55 operations each and one surgeon performed 50 procedures. Isolated posterior capsular tear occurred in 1 case and zonules were ruptured in another. Posterior capsule tear or zonular dehiscence leading to vitreous loss occurred in 6 patients $(3.8 \%)$ (Table I). Posterior chamber lenses were implanted in all but 1 eye; in this case secondary lens implantation at a later date was considered desirable. Re-intervention was necessary in 2 patients and included anterior vitrectomy and repositioning of the lens implant in 1 case and the secondary lens implantation.

Other complications included peaked pupil, minor intraocular lens decentration, retraction of capsulorhexis and central corneal oedema (Table II). A localised choroidal haemorrhage occurred in 1 patient which resolved within 6 weeks without any residual visual impairment.
Table I. Incidence of capsular lesions and vitreous loss in 160 phacoemulsification procedures

\begin{tabular}{lcc}
\hline & No. of cases & Percentage \\
\hline Isolated posterior capsule lesion & 1 & 0.6 \\
Isolated zonular lesion & 1 & 0.6 \\
Vitreous loss & 6 & 3.8 \\
Surgical re-intervention & 2 & 1.2 \\
\hline
\end{tabular}

Table II. Other complications of 160 phacoemulsification procedures

\begin{tabular}{lcc}
\hline & No. of cases & Percentage \\
\hline Corneal oedema & 1 & 0.6 \\
Peaked pupil & 1 & 0.6 \\
Minor IOL decentration & 1 & 0.6 \\
Retraction of capsulorhexis & 1 & 0.6 \\
Localised choroidal haemorrhage & 1 & 0.6 \\
Iris prolapse & 0 & 0 \\
Major IOL decentration & 0 & 0 \\
Nucleus loss & 0 & 0 \\
Retinal detachment & 0 & 0 \\
\hline
\end{tabular}

IOL, intraocular lens.

Iris prolapse, major lens implant decentration, loss of nucleus and retinal detachment were not encountered.

Eighty-eight per cent of all patients achieved a corrected visual acuity of $6 / 12$ or better. When cases with preexisting ophthalmological disease were excluded, $94 \%$ had a final corrected visual acuity of $6 / 12$ or better. Of the 20 patients whose vision could not be improved to beyond 6/12, 10 had diabetic maculopathy, 4 age-related macular degeneration, 4 cystoid macular oedema and 1 corneal oedema. There was 1 case of previously unsuspected ischaemic optic neuropathy.

\section{DISCUSSION}

Phacoemulsification is now a well-established method of cataract surgery.' It is generally agreed that uncomplicated phacoemulsification achieves good visual results and is associated with reduced surgically induced astigmatism. ${ }^{3.7 .8}$ In the United Kingdom there has been a progressive change towards small-incision cataract surgery in recent years. The change initially started at the level of the experienced consultant surgeon. However, with the increased availability of equipment and expertise the procedure is now routine in many departments. As a result registrar-grade surgeons are performing phacoemulsification at an increasing rate. Various reports have studied the complications and visual outcome of this procedure in the hands of ophthalmology residents in the United States. ${ }^{4.5}$ To our knowledge there are no reports in the literature concerning the complications resulting from registrars performing phacoemulsification in Britain.

Reports of vitreous loss during the learning curve period of experienced and novice ophthalmic surgeons from the early days of phacoemulsification suggested an increased complication rate. Kelman ${ }^{2}$ reported a $16 \%$ incidence of vitrous loss during the learning period. A similar figure was reported by other surgeons. Improvements in the design of surgical instruments, introduction of viscoelastics, continuous curvilinear capsulorhexis, hydrodissection and improved lens implant design have all 
contributed to making phacoemulsification a safer procedure. The technique has evolved as the cumulative experience of the experts increases. There is now a larger number of experienced phaco surgeons and teachers, making direct supervision and teaching possible. Not surprisingly, more recent reports indicate a lower incidence of complications. In 125 procedures Pedersen ${ }^{6}$ found a $2.1 \%$ incidence of vitreous loss and a $4.9 \%$ incidence of posterior capsule tear. Kershner" reported an $8 \%$ capsular tear rate in 1000 cases using 'can-opener' capsulotomy and $4 \%$ using capsulorhexis. Allinson et al. found a vitreous loss incidence of $14.7 \%$ in operations performed by third year ophthalmology residents learning phacoemulsification. Cruz et al. ${ }^{5}$ reported a vitreous loss rate of $5.5 \%$ and posterior capsule tear rate of $9.9 \%$. Other studies ${ }^{(1)-13}$ demonstrated a rate of vitreous loss during the residents' learning period for extracapsular surgery that is similar to that of phacoemulsification.

In this series the rate of vitreous loss was $3.8 \%$ and, overall, posterior capsular tear occurred in $5.6 \%$ of the cases. Eighty-eight per cent of all patients achieved a corrected visual acuity of $6 / 12$ or better. When patients with pre-existing ophthalmological disease were excluded, $94 \%$ had a final corrected visual acuity of $6 / 9$ or better. As reduced surgically induced astigmatism with phacoemulsification is already well documented, analysis of astigmatism was not included in the present report.

This series compares favourably with other reports of the complications of phacoemulsification performed by surgeons-in-training. ${ }^{4.5}$ One factor may be the greater previous extracapsular cataract surgery experience in our surgeons. This is logical as certain surgical principles are common to many intraocular procedures and a knowledge of these aids in the learning of any new technique. In addition, extracapsular cataract surgery provides an opportunity to practise various steps that are also required for phaco surgery such as capsulorhexis, hydrodissection, automated irrigation and aspiration and intraocular lens implantation. Another difference between this and other reports is the higher numbers of procedures that each surgeon performed. From previous reports it appears that complication rates decreases with increasing surgical experience.

Because a significant number of cataract operations in the United Kingdom are performed by the registrar grade, a good surgical training programme which reduces the complication rate will also influence the overall pattern of ocular morbidity associated with cataract surgery. Pearson and colleagues" ${ }^{11}$ reported a reduction in the rate of vitreous loss during planned extracapsular surgery performed by residents from $10.3 \%$ to $3.2 \%$ following the introduction of a new surgical training programme. A good training programme will include theoretical and practical teaching as well as step-by-step wet laboratory and real situation practice under supervision. As far as the surgeon-in-training is concerned, preparation is an essential part of transition to phacoemulsification. Good knowledge and experience of principles of ophthalmic microsurgery as a whole, as well as theoretical knowledge about phaco techniques, instruments and the machine are important first steps. Some manoeuvres such as hydrodissection, capsulorhexis and automated irrigation and aspiration can be practised during extracapsular surgery. Good case selection helps avoid difficult cases which should really be left for the advanced surgeon, thus reducing unnecessary morbidity. Finally, close supervision by an experienced phaco surgeon is important in order to avoid serious complications and to improve surgical technique by means of feedback.

In conclusion, this study documents an acceptable complication rate during the phacoemulsification learning period of registrars, indicating that teaching of this procedure to a surgeon-in-training can be safe provided there is a well-structured surgical training programme, adequate experience in extracapsular surgery and supervision.

Key words: Phacoemulsification. Surgeon-in-training, Surgical complication, Vitreous loss.

\section{REFERENCES}

1. Leaming DV. Practice styles and preferences of ASCRS members: 1990 survey. J Cataract Refract Surg 1991;17: 495-502.

2. Kelman CD. Symposium: phacoemulsification. Summary of personal experience. Trans Am Acad Ophthalmol Otolaryngol 1977;78:OP35-8.

3. Seward HC, Dalton R, Davis A. Phacoemulsification during the learning curve: risk/benefit analysis. Eye 1993;7:164-8.

4. Allinson RW, Metrikin D, Fante R. Incidence of vitreous loss among third year residents performing phacoemulsification. Ophthalmology 1992;99:726-30.

5. Cruz OA, Wallace GW, Gay LA, Matoba AY, Koch DD. Visual results and complications of phacoemulsification with intraocular lens implantation performed by ophthalmology residents. Ophthalmology 1992;99:448-52.

6. Pederson O. Phacoemulsification and intraocular lens implantation in patients with cataract. Acta Ophthalmol (Copenh) 1990;68:59-64.

7. Palin SL. Comparison of induced astigmatism with phacoemulsification and extracapsular cataract extraction. J Cataract Refract Surg 1987;13:274-8.

8. Steinert RF, Brint SF, White SM, Fine IH. Astigmatism after small incision cataract surgery. Ophthalmology 1991;98: 417-23.

9. Kershner RM. Embryology, anatomy and needle capsulotomy. In: Koch PS, Davison JA, editors. Textbook of advanced phacoemulsification techniques. New Jersey: Slack International, 1991;35-48.

10. Sappenfield DL, Driebe WT. Resident extracapsular cataract surgery: results and a comparison of automated and manual techniques. Ophthalmic Surg 1989;20:619-24.

11. Pearson PA, Owen DG, Van Meter WS, Smith TJ. Vitreous loss rates in extracapsular cataract surgery by residents. Ophthalmology 1989;96:1225-7.

12. Browning DJ, Cobo LM. Early experience in extracapsular cataract surgery by residents. Ophthalmology 1985;92: 1647-53.

13. Straatsma BR, Meyer KT, Bastek JV, Lightfoot DO. Posterior chamber intraocular lens implantation by ophthalmology residents: a prospective study of cataract surgery. Ophthalmology 1983;90:327-35. 